\title{
Role of Social Implications in Endemic Fluorosis among People Living In Ananthapur District, Andhra Pradesh
}

\author{
Sreenivas Naik B ${ }^{1}$, Govindu $\mathrm{S}^{2}$, Srinivasan $\mathrm{K}^{3}$ \\ ${ }^{1}$ (Department of Community Medicine, Government Medical College, Anantapuram). \\ ${ }_{2}^{2}$ (Department of Community Medicine, Government Medical College, Anantapuram). \\ ${ }^{3}$ (Department of Community Medicine, Government Medical College, Anantapuram).
}

\begin{abstract}
This study has undertaken to promote and protect the health and prevent the disease to some extent and thus help in implementing the need based preventive measures in affected community by aiming to study the social implications among the population residing in the endemic area of fluorosis. Patient details including age, sex, address, literacy, occupation, socioeconomic status, knowledge, attitude, practices towards fluoride related products or water and its social implications were collected. Water samples were sent to laboratory for testing fluoride content and Analysis of various social implications was done. $32.4 \%$ respondents felt that health problems are more with fluorosis. 23.5\% felt fluorosis has negative job prospects due to disability and restricted mobility. $22.6 \%$ felt that it affects marital disharmony. $8.8 \%$ had negative perception about the future and $7.8 \%$ felt that it affects intelligence and education. Children truant and frequent drop out due to stigma and low esteem. $4.9 \%$ expressed no influence in the life. The social and economic ramifications of a population affected by fluorosis are enormous. These problems are further compounded by economic stress. It is a fact that fluorosis through early detection and practice of interventions it is an easily preventable disease.
\end{abstract}

Keywords: Endemic fluorosis, Social implications.

\section{Introduction}

The term "FLUOROSIS" describes a state of toxicity of this trace element, 'FLUORINE', which when ingested in high doses either through water or through any other sources causes clinical manifestations. Fluorine is the most electronegative and reactive of all elements hence never found in nature as fluorine [1]. It has a strong tendency to form complexes with heavy metal ions in aqueous solutions. The toxic potential of inorganic fluorides is mainly associated with this behaviors and the formation of insoluble fluorides. Fluoride is the strongest oxidizing agent known.

The Bureau of Indian Standards (BIS) [2] gives permissible limit of Fluoride for human consumption is $0.7-1.2 \mathrm{ppm}$ with a rider "lesser the fluoride the better, as fluoride is injurious to health". The global prevalence of fluorosis is reported to be about 32\% [3]. The magnitude of the problem of fluorosis in India is estimated to the tune of 66.62 million rural population (9.6\%) at risk, of which an estimated 6 million are children below the age of 14 years with overtly visible signs of fluorosis [4].

This study is undertaken in a small village at Ananthapuram district which is located in the southern part of Andhra Pradesh State in India. Andhra Pradesh is considered as highly endemic area and categorized under category III in India according to severity and prevalence fluorosis.

This study has undertaken to promote and protect the health and prevent the disease to some extent and thus help in implementing the need based preventive measures in affected community by aiming to study the social implications among the population residing in the endemic area of fluorosis.

\section{Materials And Methods}

A Prospective study was done on endemic fluorosis in the period of September to December 2016 among patients living in begarla village near by Anantapuram district. The study was carried and analyzed at Department of Community Medicine, Government Medical College, Anantapuram. Ethical committee has approved to do this study. Informed consent has taken from all the selected population.

A Total of 102 households covering the 500 population residing in the endemic fluorotic area have been selected by systematic random technique. Each of the participant in this study was studied and examined to notice clinical features related to fluorosis.

Patient details including age, sex, address, literacy, occupation, socioeconomic status, knowledge, attitude, practices towards fluoride related products or water and its social implications were collected. Details regarding water source, type of staple food, agricultural practice using fluoride rich pesticide, any past history of carcinogenic/ teratogenic/mutagenic effects occurred in their family [5]. All these were recorded

Water samples were sent to laboratory for testing fluoride content using Ion-Selective Electrode Technology to find the precise concentration, the most common procedure to quantify free fluoride anion. 
Analysis was done. The statistical tests used such as chi square are done with relevant software like Epiinfo 2000. The results were tabulated interpreted and reported with relation to the available literature and discussed.

\section{Results}

A Total of 500 individuals were selected to do this study. Most of them were in the age group of 15-45 years, was $260(52 \%)$ followed by $117(23.4 \%)$ were 5-15 years, $88(17.6 \%)$ were $>45$ years, $35(7 \%)$ were $<5$ years. Out of 500 selected population $342(68.4 \%)$ were illiterates and $158(31.6 \%)$ were literates.

Out of 500 selected individuals, $453(90.6 \%)$ members have fluorosis related clinical features. Majority of the respondents believed that fluorosis is water related disease, was $260(56 \%)$ persons. $117(25.1 \%)$ respondents were not aware of the cause of disease. 88 (19\%) respondents believed that fluorosis is caused due to food habits (Table.1). The statistical difference between fluorosis patients and normal persons is significant with $\mathrm{p}$ value of $\leq 0.002$, with yates correction $=9.12$.

Table.1 Assessment of Awareness among Population regarding Fluorosis

\begin{tabular}{|l|l|l|l|}
\hline Causation awareness & Fluorosis affected persons & Normal Persons & Total \\
\hline Not Aware & $109(24.1 \%)$ & $8(66.7 \%)$ & $117(25.1 \%)$ \\
\hline Water related & $256(56.5 \%)$ & $4(33.3 \%)$ & $260(56 \%)$ \\
\hline Food related & $88(19.4 \%)$ & - & $88(19.1 \%)$ \\
\hline Air related & - & - & - \\
\hline Total & $453(100 \%)$ & $12(100 \%)$ & $500(100 \%)$ \\
\hline
\end{tabular}

Among practitioners of defluoridation technique $77.3 \%$ were showing fluorosis manifestations and $22.7 \%$ are normal. Among who practices boiling water to be a method, $94 \%$ are suffering from fluorosis manifestations and $6 \%$ are normal. Among those not using any of the methods, $92.4 \%$ are suffering from fluorosis manifestations and $7.6 \%$ are found normal (Fig.1\&2).

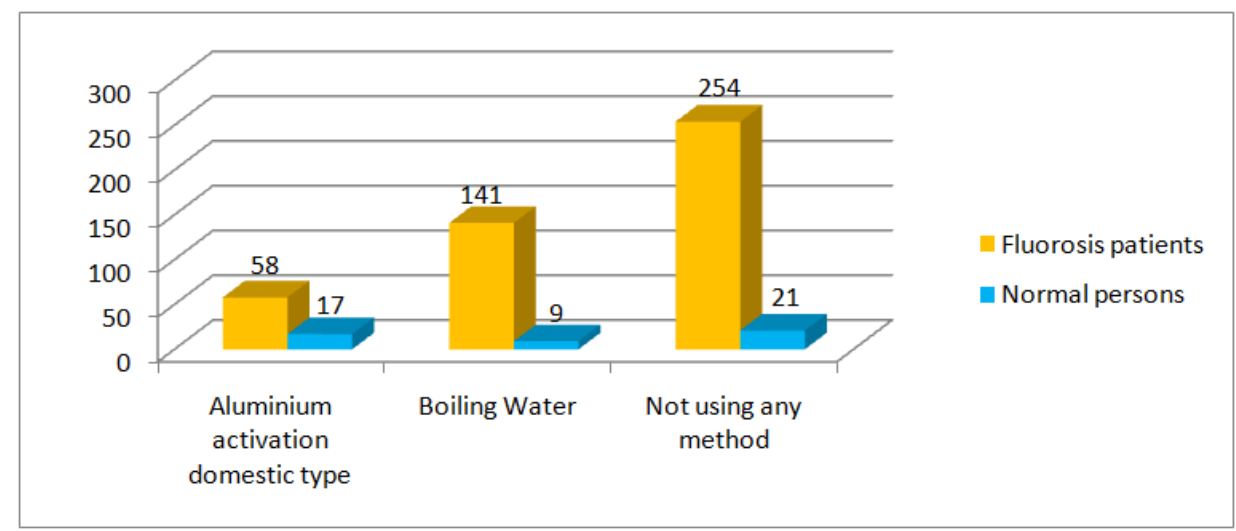

Fig No.1 Different types of defluoridation techniques used

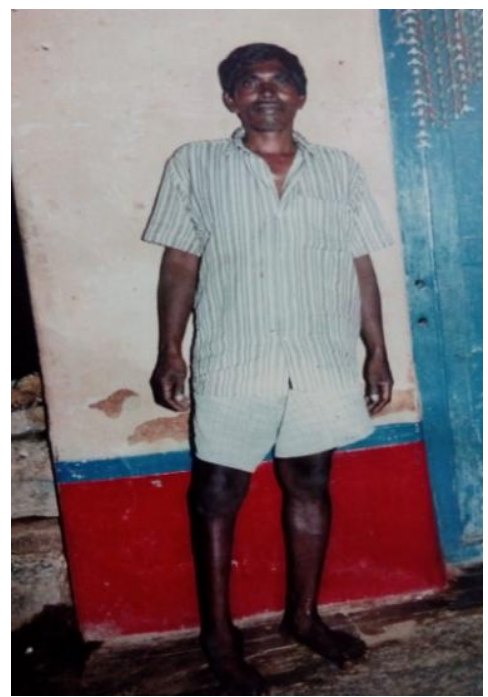

Fig.2 showing person with skeletal fluorosis 
$32.4 \%$ respondents felt that health problems are more with fluorosis. $23.5 \%$ felt fluorosis has negative job prospects due to disability and restricted mobility. $22.6 \%$ felt that it affects marital disharmony. $8.8 \%$ had negative perception about the future and $7.8 \%$ felt that it affects intelligence and education. Children truant and frequent drop out due to stigma and low esteem. $4.9 \%$ expressed no influence in the life (Table.2).

Table.2 Perception regarding Fluorosis effects on prime facets of life as expressed by head of each House hold.

\begin{tabular}{|c|c|c|c|}
\hline S. No. & Facets of life & No. of Persons & Percentage $(\%)$ \\
\hline 1 & Negative Job Prospects & 24 & 23.5 \\
\hline 2 & Health problems & 33 & 32.4 \\
\hline 3 & Marital disharmony/ marriage denial & 23 & 22.6 \\
\hline 4 & Education & 8 & 7.8 \\
\hline 5 & Negative perception of future & 9 & 8.8 \\
\hline 6 & No influence & 5 & 4.9 \\
\hline
\end{tabular}

$60.8 \%$ felt that there are social problems like restricted social mobility, unable to participate sociofunctions and loneliness and also dental fluorosis is seen an aesthetic and social problem. $39.2 \%$ felt it has impact on economic aspect as the disease cripples not only the productive age group but also the live stock which is their precious property for the agricultural farmers. $37.3 \%$ felt there are psychological problems like low self - esteem and depression and adolescents being introvert by nature (Table.3).

Table.3 Prevalence of Social Implications among Selected Population

\begin{tabular}{|c|c|c|c|c|c|c|}
\hline S.No. & Social Implications & Present & Percentage & Absent & Percentage & Total \\
\hline 1 & $\begin{array}{c}\text { Negative Attitude towards the } \\
\text { disease }\end{array}$ & 56 & $54.9 \%$ & 46 & $45.1 \%$ & 102 \\
\hline 2 & Discrimination & 32 & $31.4 \%$ & 70 & $68.6 \%$ & 102 \\
\hline 3 & Denial of marriage prospects & 36 & $35.3 \%$ & 66 & $64.7 \%$ & 102 \\
\hline 4 & Affect child IQ & 51 & $50 \%$ & 51 & $50 \%$ & 102 \\
\hline 5 & Social problem & 62 & $60.8 \%$ & 40 & $39.2 \%$ & 102 \\
\hline 6 & Dependency & 22 & $21.6 \%$ & 80 & $78.4 \%$ & 102 \\
\hline 7 & Work denial & 61 & $59.8 \%$ & 41 & $40.2 \%$ & 102 \\
\hline 8 & Psychological problems & 38 & $37.3 \%$ & 64 & $62.7 \%$ & 102 \\
\hline 9 & Stigma & 21 & $20.6 \%$ & 81 & $79.4 \%$ & 102 \\
\hline 10 & Economic repercussions & 40 & $39.2 \%$ & 62 & $60.8 \%$ & 102 \\
\hline
\end{tabular}

\section{Discussion}

Fluorosis is a dreadful, painful, slow progressive, crippling malady caused by entry of excess fluoride, fluorine and/or hydrofluoric acid into the body. Fluoride affects every organ, tissue and cells in the body and results in 3 forms of fluorosis: Dental fluorosis, Skeletal fluorosis and Non skeletal fluorosis. Fluorosis ranks high among the major environmental health problem.

Pathophysiology of fluorosis: Ingestion of fluoride causes decrease in the ionised calcium. This hypocalcemia leads to CHANGES in internal milieu of the body to maintain the calcium levels and leads to secondary hyperparathyroidism. The increased parathyroid hormone causes increased activity of osteoclasts in bone by activating membrane bound 3'5' cyclic ATP. This increased osteoclastic activity causes, increases in citric acid and lactic acid released from ruffled border of osteoclasts. Release of lysosomal enzymes which favors depolymerization of glycoprotein of bone and cartilage, due to increase in hydrogen ion concentration. This causes reduced collagen triple helix stability and mineral binding capacity, in turn calcium is liberated into the serum. Simultaneously led to the elevation of the serum mucoprotein or polysaccharide levels. The net result of degradation of ground substance in bones and other calcified tissues like teeth leads to symptoms of fluorosis like, delayed eruption of teeth, dental fluorosis, clinical fluorosis, premature ageing etc. [6-8].

The present study findings of social implications of the fluorosis and its influence on prime facets of life a similar like in any other fluorotic belt as implications are well acknowledge and majority of the respondents had the perception that fluorosis impairs life severely and has a definite impact on not only on health but marriage, occupation, future prospects are also affected. This study supported by H Jones et al in their book water supply and sanitation access and used by physically disabled people.

Negative social implications of disabled people can result in various social policies and also affects the attitudes of individuals affected by fluorosis [9]. Few studies also reported that awareness and practices of society influences discriminatory social implications than attitudes of individuals [10]. Tobis 2000 et al [11] mentioned that in countries of soviet union institutionalized segregation and discrimination is harmful, costly and intractable. Some of the institutional barriers are less obvious for example marriage where role of housewife and its abundant domestic task. 
Few authors documented that there is a least accessible to education for disabled women and also they are largely isolated and invisible [12,13]. Disabled persons also have less opportunities for skills training or income generating activities which could leads to dependency [14] and even forced to be beg [15].

This study indicates that disability due to fluorosis may also have similar influences in the life of the victims. But the perception of this disability varies with the severity of the disability. This might be reflected in the attitude of the people residing in endemic fluorotic areas.

\section{Conclusion}

The social and economic ramifications of a population affected by fluorosis are enormous. Affected people lead a very poor quality of life that often borders on a vegetative state owing to a deteriorating health condition. They present psycho sociological problems for themselves and their families. These problems are further compounded by economic stress. Coupled with this it has no cure. It is a fact that fluorosis through early detection and practice of interventions it is an easily preventable disease.

\section{Acknowledgements}

I am very thankful to all authors of published journals, thesis and also editors of books from where $\mathrm{i}$ got the literature, helped me to do this research work.

\section{References}

[1]. AG Sharpe, Inorganic chemistry, 3rd edition. 1992. ELBS publications, pp. 400.

[2]. IS : 10500-1991. Indian Standards specification for drinking water. Bureau of Indian stnadards (BIS) New Delhi, India

[3]. A Mittal, N Trivedi, SK Gupta, S Kumar, RK Gupta, Radiological spectrum of endemic fluorosis : relationship with calcium intake,

[4]. AK Susheela, Treatise on Fluorosis, revised 2nd ed. Published by Fluorosis research and rural development foundation, New Delhi, 2003.

[5]. P Granjean and G Thompsen, Reversibility of skeletal fluorosis, Br J Ind Med, 40, 1983, 456-461.

[6]. SK Gupta, Environmental health perspective of fluorosis in children Jaipur, Rajasthan, University of Rajasthan, 1999.

[7]. M McIvor, Acute Fluoride toxicity : Pathophysiology and management, Drug Saf, 5,1990,79-85.

[8]. J Yiamouyianis, Fluoride: the ageing factor, Health Action Press, Ohio, 1986.

[9]. UN (2002b) International Plan of Action on Ageing. Adopted at the UN Conference on Ageing, Madrid, April 2002, United Nations: New York.

[10]. M Oliver, Disabled People, In: Alcock et al, 1998.

[11]. D Tobis, Moving from Residential Institutions to Community Based Social Services in Central and Eastern Europe and the Former Soviet Union. World Bank: Washington, US, 2000.

[12]. DAA. Summary of material recorded in the DAA Human Rights Database as at 4.4.01. Disability Awareness in Action: London. (DAA website), 2001.

[13]. J Seeley, Recognising Diversity: Disability and rural livelihoods approaches in India. Natural Resource Perspectives No.72. The Overseas Development Institute: London, 2001a.

[14]. TL Singleton, ML Breslin, and C Lewis, Gender and Disability: a Survey of Inter Action Member Agencies. Mobility International UNSA (MIUSA).

[15]. P Coleridge, Community based rehabilitation in a complex emergency: study of Afghanistan, Selected Readings in Community based Rehabilitation, Series 2. Disability and Rehabilitation Issues in South Asia. Asia Pacific Disability Rehabilitation Journal, 2002, pp.35-49. 